\title{
A conversation with Robert Lefkowitz, Joseph Goldstein, and Michael Brown
}

$T$.

oday we shift the format of our Conversations with Giants in Medicine and allow three of our most charismatic giants (Robert Lefkowitz, Joseph Goldstein, and Michael Brown) to interview each other (Figure 1). Lefkowitz (Duke University) is known for his seminal discoveries in understanding $G$ protein-coupled receptor function. The legendary partnership between Brown and Goldstein (University of Texas Southwestern Medical Center) has spanned four decades. Together they were awarded the 1985 Nobel Prize in Physiology or Medicine acknowledging their discovery of the LDL cholesterol receptor and its role in the regulation of cholesterol metabolism. The full interview can be seen on the JCI website, http://www.jci.org/kiosk/cgm.

Lefkowitz: I'm delighted to be here, particularly with two very close friends and colleagues who have always been scientific heroes of mine. I want to speak a little about our upbringing, since it is a little different for all of us. I grew up in the Bronx and first developed an interest in becoming a physician when I was in the third grade, inspired by my family physician, who just captivated me. How did you both get started?

Goldstein: I was brought up in a town called Kingstree, South Carolina, that had about maybe 3,500 people. I went to a high school that had 60 students. In those days, there was complete segregation. It was an all-white high school, but I had really good teachers who focused on reading, writing, and arithmetic. And I had a great chemistry teacher. I guess that my first real interest in science was chemistry in high school.

Brown: I was born in Brooklyn. My motivation for medicine came from my father. He kept telling me that the only person who doesn't have a boss is a doctor. And in his community, the doctors were the highest, the most respected people. And in high school, I became an amateur radio operator building transmitters and receivers. And so, in the middle of the night, plugging it in and blowing every fuse in the house, and then you had to go back and sort of retrace your steps and figure out where you went wrong. And that's basically what I've done ever since in the lab.

Lefkowitz: At the time when I entered medical school, I really had no serious intention of ever being a scientist. I mean, my goal was to be a physician, just like the family physician who had inspired me. Was it your thought you would become a biomedical scientist or that you would primarily be a physician?

Goldstein: As medical students, we would inject patients with bromsulphalein (BSP) to assess liver function. There was a complicated assay for the conjugated form of BSP. I was making a standard curve of this BSP using the spectrophotometer, and I had the wrong wavelength. I found something that my professor, Burton Combs, who was looking over my shoulder, had never seen before. To make a long story short, I figured out a way that one could easily measure the conversion of BSP to BSP glutathione. And so, I wrote a couple of papers on this as a medical student, and it was really my first introduction to discovery. I was hooked on science.

Brown: I wanted to be a physician. But back in those days, in medical school at University of Pennsylvania, the whole attitude was if you're very good, you'll be a very good doctor. If you're really great, you'll be a professor. And then, it was at the NIH where I got my first sort of eureka moment. I was working in a lab with Earl Stadtman, and I made a chance observation, and I got this kind of a sense of "Wow, this is incredible." It really doesn't matter in retrospect how important the finding is. If you can just have that eureka moment, no matter how trivial the finding is, and appreciate that in that moment, you know something that nobody else knows.

Lefkowitz: Now, one of the most remarkable things about the two of you is your scientific partnership. I'm curious: how did this partnership get started, and how in the world did it persist all of these years?

Brown: When I was accepted at MGH, I was the first person in eleven years from Penn that had been accepted, because it was the most competitive. There were only twelve interns. A week later they sent a list of my fellow interns. And there was this guy, Joe Goldstein from Southwestern Medical College from Dallas, Texas. I thought it was a Bible school. And I figured, well, if they're accepting this guy, then maybe nobody applied this year.

Goldstein: Mike and I were both interns, and we were in the emergency room. Those were the days when we were on every other night, and you really had to work hard. Both of us were interested in metabolism at the time, and I remember very specifically, we had a patient who came in with meningitis who had lipodystrophy. And neither one of us knew very much about lipodystrophy, so we started talking.

Brown: I remember admiring Joe's intellect and experience very early. Within the first two or three days of residency, it was clear that he knew more than anybody else, not only in the internship group, but more than most of the senior residents and half of the faculty. It was clear that this guy was going someplace, and I just decided to ride along.

Lefkowitz: How did you come to the actual problem that you wanted to study?

Goldstein: We went to the NIH, all three of us were clinical associates, even though we worked in labs. I worked in Marshall Nirenberg's lab working on the end stages of protein synthesis, but we also had to see patients. Two of the first patients that I saw in the heart institute were this brother and sister that had homozygous familial hypercholesterolemia (FH). We came up with the idea that maybe the most logical defect would be in the enzyme HMG-CoA reductase.

Brown: Well, let me just start by saying a word about NIH, because it meant a lot to all three of us; it was magical. If you look at the achievements of people who went through the NIH at that time, it is remarkable, and I think it's because of the culture.

Lefkowitz: I want to interject that in our group of clinical associates, which was quite small, in addition to the three of us was Harold Varmus, Alfred Gilman, Ferid Murad, Stan Prusiner, Ed Skolnik, and Tom Caskey.

Goldstein: All of us were spread on only two floors, and we were all MDs with very little experience. And then, there were these giants, like Marshall Nirenberg, Chris Anfinsen, Earl Stadtman, Ira Pastan, and Jesse Roth.

Lefkowitz: Virtually almost the entirety of our generation of physicians who became basic researchers emanated from that institution at that time. And we all met each other. I know Joe was going back to Dallas because he had basically been knighted by Don Seldin to come back 


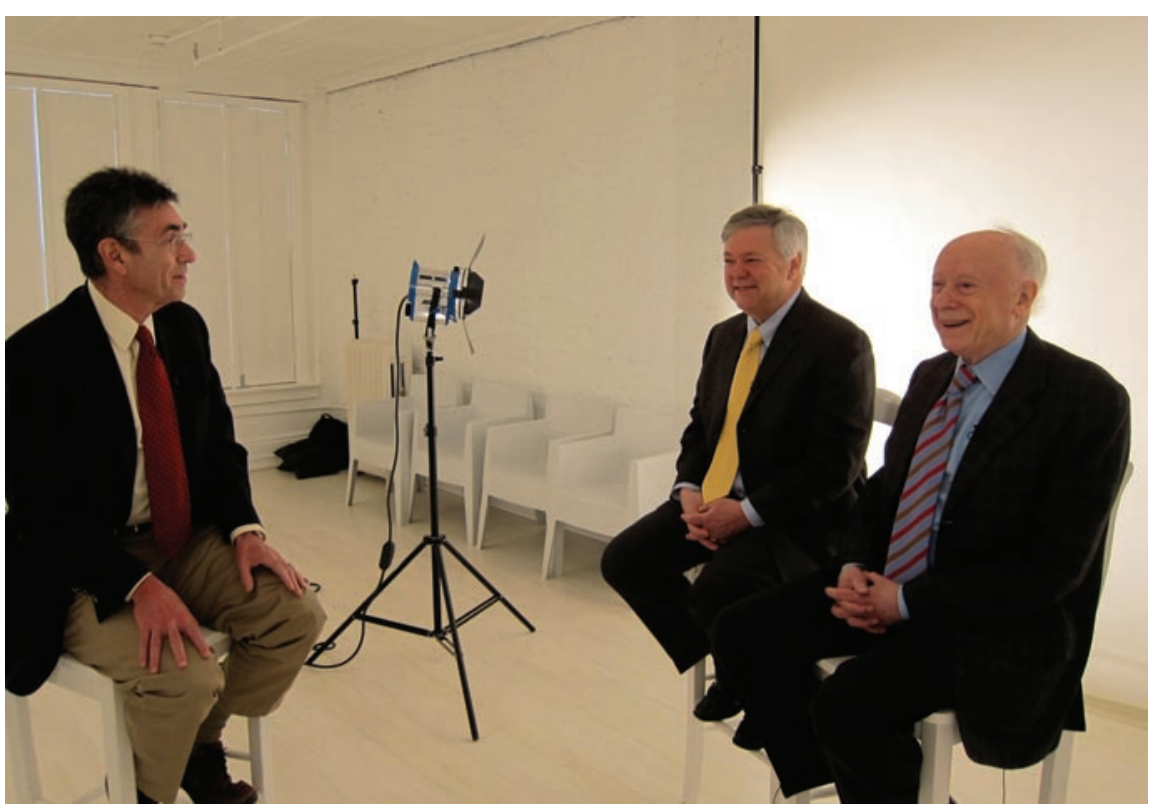

Figure 1

Lefkowitz, Brown, and Goldstein interviewing each other at the Film Annex in New York City, April 2012. Image credit: Ushma Neill.

there; what happened to you, Mike? How did you wind up in Dallas?

Brown: Well, Joe kept telling me what a wonderful place Southwestern was. And I met Seldin, and he was just the most imposing person I'd ever met. Just in terms of erudition not only in medicine but also in science and was incredibly inspirational. So, I decided to give Southwestern a try, even though I still thought it was a Bible school. And we started working on HMG-CoA reductase. But when Joe was in Seattle, he learned about tissue culture. And so the idea was, we would study the regulation of the enzyme in cultured fibroblasts from normal children and from children with FH. In fact, Joe wrote a grant on this, and it was turned down because everybody said the only important way to study cholesterol was in the liver, and we wanted to study it in fibroblasts.

Goldstein: So, we got skin fibroblasts from a patient with $\mathrm{FH}$, and Mike and I began a ritual that we carried out, I would say at least for twenty years, where we would meet every day and we would plan the experiments. And then in those days, because we were both impatient, the cells would be harvested and the assay would be done that same day, so we would know the results quickly. The first experiment was comparing the HMG-CoA reductase activity in those cells versus normal fibroblasts plus and minus LDL, and we got this really dramatic result. There was a hundredfold difference in the presence of LDL: the HMG-CoA reductase was a reflection of cholesterol synthesis.

Lefkowitz: If you look at our three careers, one thing that we have in common is this element of focus. I often tell people that you could take most of the experiments going on in my laboratory right now, and if you went back to the experiment that led to that, and then the one that led to that, and the one that led to that, you could go back to the day I opened my lab, without any real jump.

Brown: The way I say it is that we never jump with two feet. We always keep one foot on solid ground. If we are exploring new areas, we keep one foot on solid ground. So, all of our work is really stemmed around cholesterol and lipids in general.

Lefkowitz: Joe once told me something that I've passed along on a number of occasions. I'm paraphrasing, but Joe once told me that the key to having one good idea is to have a hundred bad ones and very quickly sort through them to find that one gem. I guess that is what happens with the two of you.

Brown: The partnership does that automatically. But I always tell our students, almost half jokingly, that $95 \%$ of the literature is wrong. The other $5 \%$ was written by us.

Lefkowitz: This seems akin to something I often tell my people. There are only three ways that people quote us: insufficiently, inappropriately, or not at all.

Brown: What about mentoring? I mean, we all do a lot of it.

Goldstein: I think the best thing that I can say about mentoring is that if you're a good role model yourself, that's the best way. Someone who is passionate about his or her work, curious, dedicated, honest, has integrity and is self-critical about data.

Lefkowitz: I very much endorse what you say about mentoring. The way to be a mentor is to put yourself out there. I try to make myself as transparent as possible. Anything that's going on, watch me. It's an apprenticeship, right? More than anything else, it's a matter of acquiring a certain sense of taste, of integrity, of how do you do things. I guess one of the most challenging things that we have to do is on the one hand, you need to demonstrate rigor, and on the other, you need to demonstrate that even $n=1$ can really turn you on because it gets you thinking. And I always make that point. Often the fellows I find are resistant to show me some data. I'll say, "You got something." They say, "Let me repeat it first." Don't repeat it first, I want to know now!

Brown: I hate it when they don't show us negative data.

Goldstein: We should hire you as a postdoctoral fellow.

Lefkowitz: I would love it. I want to conclude with one last story, which I think illustrates a little bit about these two guys. Joe and I were once flying from Dallas to San Francisco, and a gentleman recognized Joe. And he says, "Oh my goodness! You're Joe Goldstein, that famous doctor who won the Nobel Prize. I read about you in the paper all the time, I'm so excited about what you do," and on and on. Joe just wanted to go under the chair. But these guys are really celebrities, and they still are recognized both among the scientific community and the lay community for everything they've done.

Goldstein: It's not as common as it used to be in Dallas - people would always see me or Mike or both of us and say, "Oh, you're the guy who won the Peace prize." We used to say, "No, we did this." Now, we just say, "Yeah."

Brown: I'll just extend with one other vignette. Very frequently, people will call me Joe, and they're always embarrassed, and I say, "Don't be embarrassed. My wife makes the same mistake."

\section{Ushma S. Neill and Howard A. Rockman}

